\title{
Notas en torno a la problemática actual de la lengua tamazight
}

Ahmed Boukous

\section{Resumen}

Partiendo del análisis de la realidad actual, social, y lingüistica, de la lengua tamazight, lengua viva pero marginada, y continuando con la observación de que lo tamazight constituye de hecho hoy un sistema de signos lingüísticos, de carácter vocal, articulado en monemas y en fonemas, es decir, es una lengua en sentido estricto, se llega a concluir en una serie de propuestas tendentes a la creación de un Instituto de Estudios y de Investigaciones Especializado en Tamaright

\section{Realidad sociolingüística}

Hay testimonios de la lengua tamazight desde hace cinco mil años en un área inmensa que abarca casi cinco millones de $\mathrm{Km}^{2}$ y que la extiende de Este a Oeste: desde la frontera de Egipto-Libia hasta las Islas Canarias; y de Norte a Sur: de la orilla meridional del Mediterráneo hasta

(*) Estas Notas se integran también en el contexto del coloquio celebrado durante el año 1991 en la Universidad de Verano de Agadir, ya que constituyen las respuestas por escrito a preguntas planteadas en el mismo. 
Mali y Níger. En este espacio geográfico, los imazighen están integrados en grupos sociales considerados de hecho comunidades lingüisticas minoritarias. En realidad, en ninguno de estos países, salvo Níger y Mali, la lengua tamazight es reconocida oficialmente como lengua nacional. La comunidad tamazightófona más importante es la de Marruecos, que representa, sin duda, más de la mitad de la población global.

En Marruecos, la situación sociolingürstica del tamazight es la de una lengua vernácula que los practicantes utilizan fundamentalmente como medio de comunicación en situaciones marcadas por la intimidad, la familiaridad, la no formalidad y, en general, en relaciones de tipo personal. A pesar de la incipiente aparición de una literatura escrita de expresión tamazight, su uso predominante está marcado en los límites de su oralidad.

En la situación lingüística que prevalece en Marruecos, la lengua tamazight presenta características sociolingüísticas que la distinguen de otras variedades también presentes en el país:

1. No está codificada. En la medida en que la norma de su uso no es explícita por ninguna instancia.

2. Es histórica. Se ha probado este testimonio en la región desde hace por lo menos cinco mil años.

3. Es autónoma respecto a la lengua árabe porque pertenece al grupo de lenguas camíticas y no semíticas.

4. Es vital, en el sentido que constituye el idioma materno de muchos millones de marroquíes que la utilizan como medio de comunicación en sus vidas cotidianas.

5. Tiene un valor simbólico en el imaginario de sus usuarios que la perciben fundamentalmente como medio de expresión de la etnicidad e identidad tamazight.

6. Es el vector de la amazighidad en el proyecto cultural del movimiento asociativo y de investigación y en el proyecto de creación literario y artístico, lo que constituye la base de la conciencia cultural amazigh.

\section{Tamazight, ¿lengua 0 dialecto?}

El tamazight es una lengua en sentido estricto si le damos a este concepto su sentido técnico, es decir, un sistema de signos lingüísticos 
Notas en tono a la problemática actual de la lengua tamazight

de carácter vocal y articulado en monemas o palabras teniendo un sentido, $y$ en fonemas o sonidos distintivos. Como toda lengua, el tamazight tiene su gramática propia cuyas reglas de funcionamiento están implícitas e interiorizadas por los usuarios nativos. Estas reglas pueden ser explrcitas con un esfuerzo de normalización de la lengua, y al igual que otras lenguas, el tamazight común no puede se considerado como un dialecto a causa de las siguientes razones:

1. No existe una lengua oficial, común, central, que sea una realización regional, como es el caso del árabe clásico en sus relaciones con los dialectos árabes.

2. No existe como lengua que funcione con variedad social, como es el caso de las formas lingüísticas específicas de las clases sociales o de las categorfas socio-profesionales en las sociedades fuertemente estratificadas.

3. No existe como lengua que sea el producto de la evolución histórica como es el caso de las lenguas romances respecto del latín.

Sin embargo los usos social e ideológico dominantes toman al tamazight como un dialccto. Esto se debe fundamentalmente al hecho de que se trata de una lengua nacional marginada por los diferentes aparatos ideológicos del Estado.

\section{Unidad y diversidad del tamazight}

Todos los obscrvadores están de acuerdo en afirmar que a pesar de la inmensidad del espacio donde es utilizado el tamazight, las estructuras fundamentales de la gramática son las mismas. En efecto, la unidad del tamazight aparece en los niveles de la fonologia, de la morfología nominal y verbal, y de la sintaxis. El léxico es prácticamente común de un extremo a otro del dominio amazigh.

Sin embargo cs innegable que la inteligibilidad entre los hablantes que pertenecen a comunidades alejadas unas de otras no se produce de una manera fácil. No puede ser de otro modo en la situación sociolingǘstica y polf́tica que vive el tamazight y que podemos esquematicamente describir así:

1. Los hablantes del tamazight están diseminados a través de un inmenso espacio e integrados en estados-naciones de "inspiración jacobina" que no reconocen su estatuto de lengua nacional, menos aún el 
de la lengua oficial, salvo Níger y Mali.

2. Además, la quiebra de la economía tradicional en las regiones rurales tamazightparlantes y el desarrollo de las emigraciones interna y exterma de los imazighen en dirección a las aglomeraciones urbanas donde son minoritarias 0 asimilados.

3. El tamazight no se beneficia, salvo Níger y Mali, de ninguna medida estatal susceptible de promoverla.

Estos son los principales factores que conducen objetivamente a la desestructuración de las bases materiales y simbólicas del uso del tamazight, creando así, por vías de consecuencia, las condiciones de una supervivencia hipotética.

\section{Perspectivas de la lengua tamazight}

Es sabido que la lengua tamazight:

1. Es una permanencia de la historicidad de la tierra africana desde milenios.

2. Forma parte integrante del patrimonio cultural de Marrue$\cos$.

3. Es la lengua de nuestra primera identidad.

4. Representa un elemento constitutivo que no se puede separar de nuestra identidad colectiva.

5. Es un dato de base de nuestro ecosistema. En consecuencia, no podemos hacer nada más que denunciar la situación a que está sometida esta lengua que ha resistido durante miles de años y que atraviesa una situación precaria y difícil que la pone en peligro en este final del siglo XX. Su supervivencia es una necesidad para toda la comunidad nacional, por eso es imperativo que sean tomadas medidas para su promoción.

De esas medidas, las más urgentes son aquellas que tienen por objetivos:

1. La elaboración de un sistema gráfico adecuado

2. La normalización de la lengua por la confección de manuales de gramática y de libros de lectura, de diccionarios de la lengua y de léxicos especializados.

3. La enseñanza de la lengua y de la cultura tamazight. Esta 
enseñanza debería intervenir, en primer lugar, al nivel de la enseñanza superior (universitaria) con el fin de formar los docentes susceptibles de encuadrar los ciclos inferiores de la enseñanza.

Estas son las tareas fundamentales que debería realizar un Instituto de Estudios y de Investigaciones Especializado en Tamazight. 